\title{
Association between mammographic features and clinicopathological characteristics in invasive ductal carcinoma of breast cancer
}

\author{
SHAN-SHAN SUN ${ }^{1-3}$, BIN ZHANG $^{1-3}$, HONG-MENG ZHAO $^{1-3}$ and XU-CHEN CAO ${ }^{1-3}$ \\ ${ }^{1}$ National Key Laboratory of Breast Cancer Prevention and Treatment, Department of Breast Cancer Surgery; \\ Departments of ${ }^{2}$ Pathology, and ${ }^{3}$ Breast Cancer Pathology and Research Laboratory, Cancer Institute and Hospital, \\ Tianjin Medical University, Tianjin 300060, P.R. China
}

Received January 10, 2014; Accepted May 5, 2014

DOI: $10.3892 / \mathrm{mco} .2014 .297$

\begin{abstract}
The aim of the present study was to evaluate the association between mammographic features and clinicopathological characteristics in invasive ductal carcinoma. A total of 231 patients were retrospectively reviewed from January, 2011 to December, 2012. Statistical analysis was performed using Fisher's exact test, $\chi^{2}$ test, Spearman's correlation and logistic regression, as appropriate. Of the 231 patients who underwent mammography, malignant calcifications were significantly more frequent in carcinomas that were human epidermal growth factor receptor 2 (HER2)-positive $(\mathrm{P}=0.001)$ or had a $>2 \mathrm{~cm}$ size tumor $(\mathrm{P}=0.006)$. The pleomorphic-type was correlated with a p53-positive status $(\mathrm{P}=0.039)$ or lymph node metastasis $(\mathrm{P}=0.048)$, whereas the indistinct amorphous-type was associated with a HER2-positive status $(\mathrm{P}=0.026)$. An evident mass was frequently observed in higher $\mathrm{Ki}-67$ expression-level tumors $(\mathrm{P}=0.002)$. In conclusion, the aforementioned correlations are noteworthy as they potentially reflect tumor attributes and may serve as a guide for treatment.
\end{abstract}

\section{Introduction}

Mammography detection is a widely-used screening technique for breast cancer (1). Typical features characteristic of invasive malignant carcinoma include evident mass, micro-calcification, architectural distortion or asymmetric density. Tumors with various clinical and pathological characteristics have different appearances on mammography, leading to variable

Correspondence to: Dr Xu-Chen Cao, National Key Laboratory of Breast Cancer Prevention and Treatment, Department of Breast Cancer Surgery, Building B, Cancer Institute and Hospital, no. 5 Huanhu Xi Road, Tianjin Medical University, Tianjin 300060, P.R. China

E-mail: cxc111111@yeah.net

Key words: mammography, breast neoplasm, clinic, invasive ductal carcinoma, pathology prognoses (2). It has been reported that HER2/neu is a factor that influences specific mammographic appearances (3). Regarding the image features of certain special histology types, Yang et al (4) compared metaplastic breast cancer and invasive ductal carcinomas (IDCs). Increasing attention has focused on the clinical and pathological characteristics of breast carcinomas, which may exhibit various types of biological behaviors over the years of treatment and prognosis (5). However, few studies have been conducted with regard to this aspect.

The aim of the present study was to investigate the association between mammographic image features and clinicopathological characteristics in IDC.

\section{Materials and methods}

Patient data and mammography studies. The clinical and pathological results and mammography reports of 231 patients were retrospectively analyzed. The mammographic appearances were assessed according to the analytical criteria of the Breast Imaging Reporting and Data System from the database of Tianjin Oncology Hospital Breast Cancer Center (6). All the patients were female, and underwent breast radical mastectomy between 2011 to 2013. Mammography screening detection was obtained prior to surgery.

Study design and conduction. Pathological information was prospectively collected according to patient age, estrogen2 level in circulation, tumor size, the grade of IDC, the molecular type of carcinoma, estrogen receptor (ER) and progesterone receptor (PR) status, HER2/neu status, Ki-67 expression level, p53 status and lymph node metastasis status. Mammograms were assessed by five radiologists who specialize in breast radiology at the Department of Oncology Center (Tianjin Medical University Cancer Institute and Hospital, Tianjin, China), without any information of the pathological results. The mammography studies were collected and divided into five groups according to the traditional identification of malignant breast cancer in general. The five groups were i) evident mass without calcifications (Fig. 1A), ii) malignant calcifications without mass (Fig. 1B), iii) evident mass with calcifications (Fig. 1C), iv) architectural distortion or asymmetric density 
A

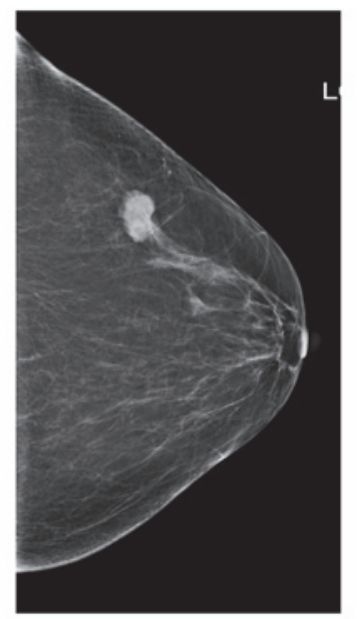

D

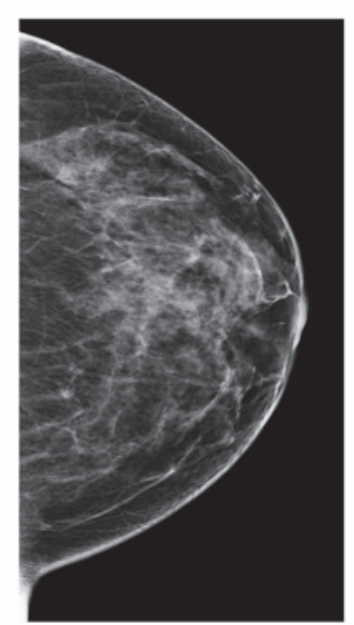

B

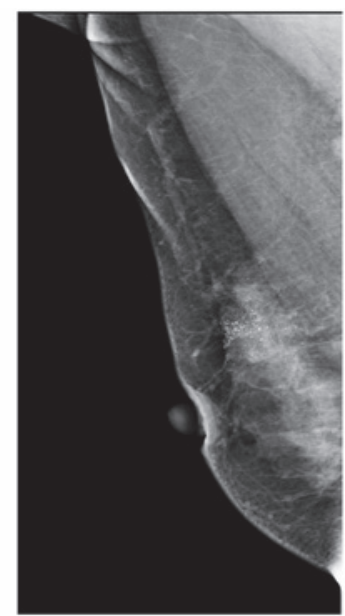

$\mathbf{E}$

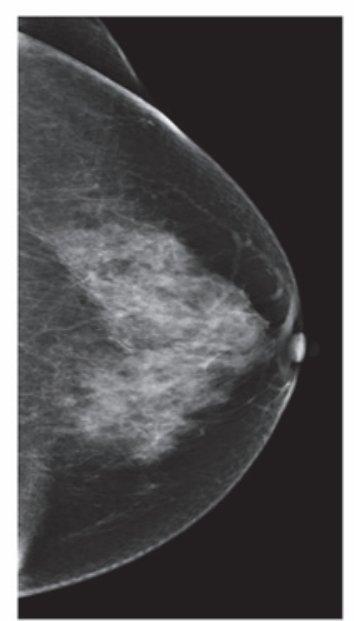

C

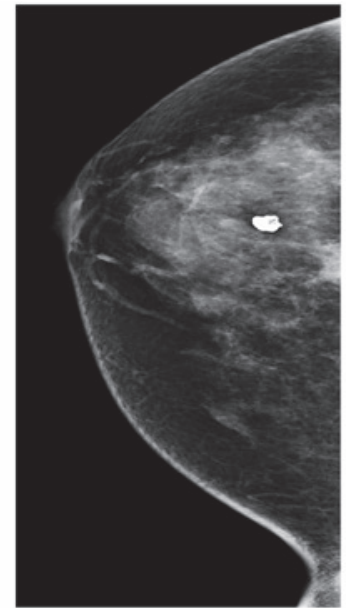

Figure 1. (A) Evident mass without calcifications; (B) malignant calcifications without mass; (C) evident mass with calcifications; (D) architectural distortion or asymmetric density without mass or calcifications and (E) no visible changes.

without mass or calcifications (Fig. 1D) and v) no visible changes (Fig. 1E), respectively.

Statistical analysis. Pathological information was correlated with mammographic appearances. The data were analyzed by the SPSS 17.0 statistical program (SPSS, Inc., Chicago, IL, USA). Statistical analysis was performed to assess the association using Fisher's exact test, the $\chi^{2}$ test, Spearman's correlation and logistic regression, as appropriate.

\section{Results}

Several factors generally associated with mammographic appearances. Table I demonstrates that there were significant differences between mammographic appearances in general and age, estrogen 2 level in circulation, tumor size, grade of IDC, HER2 expression status, Ki-67 expression index and the molecular type of the tumor $(\mathrm{P}=0.005,0.044,0.020,0.037$, $0.001,0.001$ and 0.013 , respectively).

Comparison of mammographic features with the immunohistochemistry labeling index of the tumor. In the HER2 group, significant differences were identified between the presence and absence of malignant calcifications and indistinct or amorphous calcifications on mammography $(\mathrm{P}=0.001$ and $\mathrm{P}=0.026)$. In the $\mathrm{Ki}-67$ index group, significant differences were identified between the presence and absence of an evident mass $(\mathrm{P}=0.002)$. In the expression of the p53 group, significant differences were identified between the presence and absence of pleomorphic calcifications on mammography $(\mathrm{P}=0.039)$. These results are shown in Tables II-V, respectively.

Comparison of mammographic features with the pathological index of the tumor. There were significant differences between the presence and absence of malignant calcifications in the size of the tumor group $(\mathrm{P}=0.006)$ (Table II). Furthermore, in the group of an evident mass on mammogram, there were significant differences between irregular and lobular or oval mass shape in various grades of IDC $(\mathrm{P}=0.001)$ (Table VI).

Comparison of mammographic features with the nodal involvement status of the tumor. In terms of the nodal involvement of the tumor, the data in Table IV demonstrated that there were significant differences between the presence and absence of pleomorphic calcifications $(\mathrm{P}=0.048)$.

\section{Discussion}

In previous years, the mammogram has become one of the most significant diagnostic approaches of breast tumor. 
Table I. Association between mammographic appearance and clinical characteristics.

\begin{tabular}{|c|c|c|c|c|c|c|c|}
\hline \multirow[b]{2}{*}{ Characteristics } & \multicolumn{5}{|c|}{ Mammographic appearance, $\%$} & \multirow[b]{2}{*}{ P-value } & \multirow[b]{2}{*}{$\chi^{2}$} \\
\hline & 1 & 2 & 3 & 4 & 5 & & \\
\hline Age, years & & & & & & 0.005 & 14.91 \\
\hline$>50$ & 26.1 & 16.8 & 51.3 & 5.0 & 0.8 & & \\
\hline$\leq 50$ & 26.1 & 31.5 & 30.6 & 7.2 & 4.5 & & \\
\hline Estrogen2 level in circulation & & & & & & 0.044 & 9.794 \\
\hline$>40$ & 26.2 & 31.0 & 32.1 & 6.0 & 4.8 & & \\
\hline$\leq 40$ & 25.9 & 19.6 & 47.6 & 6.3 & 0.7 & & \\
\hline Tumor size, $\mathrm{cm}$ & & & & & & 0.020 & 11.668 \\
\hline$\leq 2$ & 29.9 & 23.9 & 32.5 & 9.4 & 4.3 & & \\
\hline$>2$ & 21.9 & 23.7 & 50.0 & 2.6 & 1.8 & & \\
\hline Lymph node status & & & & & & 0.365 & 4.319 \\
\hline Negative & 27.7 & 23.1 & 37.7 & 8.5 & 3.1 & & \\
\hline Positive & 23.8 & 24.8 & 45.5 & 3.0 & 3.0 & & \\
\hline Grade of IDC & & & & & & 0.037 & 16.393 \\
\hline I & 37.5 & 16.7 & 29.2 & 16.7 & 0.0 & & \\
\hline II & 24.8 & 28.0 & 37.9 & 5.6 & 3.7 & & \\
\hline III & 23.9 & 13.0 & 58.7 & 2.2 & 2.2 & & \\
\hline Estrogen receptor & & & & & & 0.561 & 2.984 \\
\hline Negative & 21.7 & 20.0 & 45.0 & 8.3 & 5.0 & & \\
\hline Positive & 27.5 & 25.1 & 39.8 & 5.3 & 2.3 & & \\
\hline Progesterone receptor & & & & & & 0.726 & 2.054 \\
\hline Negative & 23.7 & 19.7 & 46.1 & 6.6 & 3.9 & & \\
\hline Positive & 27.1 & 25.8 & 38.7 & 5.8 & 2.6 & & \\
\hline HER2 expression status & & & & & & 0.001 & 19.993 \\
\hline Negative & 36.3 & 27.5 & 22.5 & 10.0 & 3.8 & & \\
\hline Positive & 20.5 & 21.9 & 51.0 & 4.0 & 2.6 & & \\
\hline Ki-67 expression index & & & & & & 0.001 & 17.650 \\
\hline$\geq 45 \%$ & 22.4 & 13.4 & 59.7 & 1.5 & 3.0 & & \\
\hline$<45 \%$ & 27.8 & 28.4 & 32.7 & 8.0 & 3.1 & & \\
\hline p53 status & & & & & & 0.066 & 8.794 \\
\hline Negative & 29.3 & 25.6 & 35.4 & 7.3 & 2.4 & & \\
\hline Positive & 18.5 & 20.0 & 53.8 & 3.1 & 4.6 & & \\
\hline Molecular type & & & & & & 0.013 & 25.423 \\
\hline Luminal A & 34.8 & 29.0 & 24.6 & 8.7 & 2.9 & & \\
\hline Luminal B & 22.5 & 23.5 & 50.0 & 2.9 & 1.0 & & \\
\hline HER2 overexpression & 18.4 & 18.4 & 53.1 & 6.1 & 4.1 & & \\
\hline Triple negative & 40.0 & 20.0 & 10.0 & 20.0 & 10.0 & & \\
\hline
\end{tabular}

Mammogram appearance: 1 , mass without malignant calcification; 2 , malignant calcification without mass; 3 , mass with malignant calcification; 4, architectural distortion or asymmetric density without mass or calcification; 5, none; IDC, invasive ductal carcinoma.

Findings of previous studies (7-10) have indicated that various types of breast tumor present different appearances on mammogram. Several typical mammographic appearances can reflect the tumor attributes and its biological behaviors, which may provide valuable information to the clinicians.
Mammographic features can be used as predictors of prognosis and pathological characteristics, which influence the subsequent treatment. Therefore, the mammographic pattern is considered a risk factor for subsequent development of breast cancer (11). 
Table II. Association between malignant calcification and clinical characteristics.

\begin{tabular}{|c|c|c|c|c|c|c|c|c|}
\hline \multirow[b]{2}{*}{ Characteristics } & \multicolumn{2}{|c|}{ Malignant calcification, $\%$} & \multirow[b]{2}{*}{$\chi^{2}$} & \multirow[b]{2}{*}{ P-value } & \multirow[b]{2}{*}{$\mathrm{r}$} & \multirow[b]{2}{*}{ Sig } & \multirow[b]{2}{*}{ HR (adjusted) } & \multirow[b]{2}{*}{$95 \% \mathrm{CI}$} \\
\hline & Positive & Negative & & & & & & \\
\hline HER2 (n=231) & & & 11.989 & 0.001 & 0.228 & 0.000 & 3.205 & $1.617-6.354$ \\
\hline Negative & 50.0 & 50.0 & & & & & & \\
\hline Positive & 72.8 & 27.2 & & & & & & \\
\hline Molecular type $(n=230)$ & & & 13.496 & 0.004 & 0.080 & 0.227 & & \\
\hline Luminal A & 53.6 & 46.4 & & & & & & \\
\hline Luminal B & 73.5 & 26.5 & & & & & & \\
\hline HER2 overexpression & 71.4 & 28.6 & & & & & & \\
\hline Triple negative & 30.0 & 70.0 & & & & & & \\
\hline p53 (n=229) & & & 3.373 & 0.066 & 0.121 & 0.067 & & \\
\hline Negative & 61.0 & 39.0 & & & & & & \\
\hline Positive & 73.8 & 26.2 & & & & & & \\
\hline Ki-67 (n=229) & & & 2.997 & 0.083 & 0.114 & 0.084 & & \\
\hline$\geq 45 \%$ & 73.1 & 26.9 & & & & & & \\
\hline$<45 \%$ & 61.1 & 38.9 & & & & & & \\
\hline Tumor size, $\mathrm{cm}(\mathrm{n}=231)$ & & & 7.567 & 0.006 & 0.181 & 0.006 & 1.913 & $1.075-3.405$ \\
\hline$\leq 2$ & 56.4 & 43.6 & & & & & & \\
\hline$>2$ & 73.7 & 26.3 & & & & & & \\
\hline
\end{tabular}

Table III. Association between breast mass and clinical characteristics.

\begin{tabular}{|c|c|c|c|c|c|c|c|c|}
\hline \multirow[b]{2}{*}{ Characteristics } & \multicolumn{2}{|c|}{ Mass, $\%$} & \multirow[b]{2}{*}{$\chi^{2}$} & \multirow[b]{2}{*}{ P-value } & \multirow[b]{2}{*}{$\mathrm{r}$} & \multirow[b]{2}{*}{ Sig } & \multirow[b]{2}{*}{ HR (adjusted) } & \multirow[b]{2}{*}{$95 \% \mathrm{CI}$} \\
\hline & Positive & Negative & & & & & & \\
\hline Age, years $(n=230)$ & & & 11.041 & 0.001 & 0.219 & 0.001 & & \\
\hline$>50$ & 77.3 & 22.7 & & & & & & \\
\hline$\leq 50$ & 56.8 & 43.2 & & & & & & \\
\hline $\begin{array}{l}\text { Estrogen } 2 \text { level } 1 \\
\text { in circulation }(n=227)\end{array}$ & & & 5.501 & 0.027 & -0.156 & 0.019 & & \\
\hline$>40$ & 26.6 & 73.4 & & & & & & \\
\hline$\leq 40$ & 58.3 & 41.7 & & & & & & \\
\hline HER2 (n=231) & & & 3.865 & 0.049 & 0.129 & 0.050 & & \\
\hline Negative & 58.8 & 41.3 & & & & & & \\
\hline Positive & 71.5 & 28.5 & & & & & & \\
\hline Ki-67 (n=229) & & & 9.969 & 0.002 & 0.209 & 0.001 & 2.741 & $1.265-5.940$ \\
\hline$\geq 45 \%$ & 82.1 & 17.9 & & & & & & \\
\hline$<45 \%$ & 60.5 & 39.5 & & & & & & \\
\hline $\begin{array}{l}\text { Grade of invasive } \\
\text { ductal carcinoma }(n=231)\end{array}$ & & & 6.405 & 0.041 & 0.128 & 0.052 & & \\
\hline I & 66.7 & 33.3 & & & & & & \\
\hline II & 62.7 & 37.3 & & & & & & \\
\hline III & 82.6 & 17.4 & & & & & & \\
\hline
\end{tabular}

CI, confidence interval; HR, hazard ratio. 
Table IV. Association between pleomorphic calcifications and clinical characteristics.

\begin{tabular}{|c|c|c|c|c|c|c|c|c|}
\hline \multirow[b]{2}{*}{ Characteristics } & \multicolumn{2}{|c|}{ eomorphic calcifications, $\%$} & \multirow[b]{2}{*}{$\chi^{2}$} & \multirow[b]{2}{*}{ P-value } & \multirow[b]{2}{*}{$\mathrm{r}$} & \multirow[b]{2}{*}{ Sig } & \multirow[b]{2}{*}{ HR (adjusted) } & \multirow[b]{2}{*}{$95 \% \mathrm{CI}$} \\
\hline & Positive & Negative & & & & & & \\
\hline HER2 (n=231) & & & 3.186 & 0.074 & 0.117 & 0.075 & & \\
\hline Negative & 15.0 & 85.0 & & & & & & \\
\hline Positive & 25.2 & 74.8 & & & & & & \\
\hline p53 (n=229) & & & 4.246 & 0.039 & 0.136 & 0.040 & 2.049 & $1.051-3.997$ \\
\hline Negative & 18.3 & 81.7 & & & & & & \\
\hline Positive & 30.8 & 69.2 & & & & & & \\
\hline Ki-67 (n=229) & & & 3.556 & 0.059 & 0.125 & 0.059 & & \\
\hline$\geq 45 \%$ & 29.9 & 70.1 & & & & & & \\
\hline$<45 \%$ & 18.5 & 81.5 & & & & & & \\
\hline Tumor size, cm $(\mathrm{n}=231)$ & & & 2.895 & 0.089 & 0.112 & 0.090 & & \\
\hline$\leq 2$ & 17.1 & 82.9 & & & & & & \\
\hline$>2$ & 26.3 & 73.7 & & & & & & \\
\hline Lymph node status $(\mathrm{n}=231)$ & & & 3.909 & 0.048 & 0.130 & 0.048 & 1.993 & $1.049-3.785$ \\
\hline Negative & 16.9 & 83.1 & & & & & & \\
\hline Positive & 27.7 & 72.3 & & & & & & \\
\hline
\end{tabular}

CI, confidence interval; HR, hazard ratio.

Table V. Association between indistinct and amorphous calcifications and clinical characteristics.

\begin{tabular}{|c|c|c|c|c|c|c|c|c|}
\hline \multirow[b]{2}{*}{ Characteristics } & \multicolumn{2}{|c|}{$\begin{array}{l}\text { Indistinct and amorphous } \\
\text { calcifications, \% }\end{array}$} & \multirow[b]{2}{*}{$\chi^{2}$} & \multirow[b]{2}{*}{ P-value } & \multirow[b]{2}{*}{$\mathrm{r}$} & \multirow[b]{2}{*}{ Sig } & \multirow[b]{2}{*}{ HR (adjusted) } & \multirow[b]{2}{*}{$95 \% \mathrm{CI}$} \\
\hline & Positive & Negative & & & & & & \\
\hline Age, years $(n=230)$ & & & 3.319 & 0.071 & -0.120 & 0.068 & & \\
\hline$>50$ & 20.2 & 79.8 & & & & & & \\
\hline$\leq 50$ & 30.6 & 69.4 & & & & & & \\
\hline $\operatorname{HER} 2(n=231)$ & & & 5.085 & 0.026 & 0.149 & 0.024 & 2.155 & $1.077-4.315$ \\
\hline Negative & 16.2 & 83.8 & & & & & & \\
\hline Positive & 29.8 & 70.2 & & & & & & \\
\hline Tumor size, $\mathrm{cm}(\mathrm{n}=231)$ & & & 3.729 & 0.068 & 0.127 & 0.053 & & \\
\hline$\leq 2$ & 19.7 & 80.3 & & & & & & \\
\hline$>2$ & 33.7 & 66.3 & & & & & & \\
\hline p53 (n=229) & & & 3.657 & 0.066 & 0.127 & 0.056 & & \\
\hline Negative & 6.1 & 93.9 & & & & & & \\
\hline Positive & 13.8 & 86.2 & & & & & & \\
\hline Ki-67 (n=229) & & & 3.497 & 0.061 & -0.124 & 0.061 & & \\
\hline$\geq 45 \%$ & 3.0 & 97.0 & & & & & & \\
\hline$<45 \%$ & 10.5 & 89.5 & & & & & & \\
\hline
\end{tabular}

CI, confidence interval; HR, hazard ratio.

It is known that specific types of breast tumor, including colloid or tubular, manifest particular appearances on mammogram $(12,13)$. However, the IDC is the most frequent histological type among breast tumors. In general, breast tumors exhibit up to five different radiological patterns corresponding to the biological heterogeneity of these tumors. 
Table VI. Association between the shape of mass and clinical characteristics.

\begin{tabular}{|c|c|c|c|c|c|c|c|c|}
\hline \multirow[b]{2}{*}{ Characteristics } & \multicolumn{2}{|c|}{ Shape of mass (\%) } & \multirow[b]{2}{*}{$\chi^{2}$} & \multirow[b]{2}{*}{ P-value } & \multirow[b]{2}{*}{$\mathrm{r}$} & \multirow[b]{2}{*}{ Sig } & \multirow[b]{2}{*}{ HR (adjusted) } & \multirow[b]{2}{*}{$95 \% \mathrm{CI}$} \\
\hline & Regular & Irregular & & & & & & \\
\hline Tumor size, $\mathrm{cm}(\mathrm{n}=155)$ & & & 4.841 & 0.036 & 0.177 & 0.027 & & \\
\hline$\leq 2$ & 61.6 & 38.4 & & & & & & \\
\hline$>2$ & 43.9 & 56.1 & & & & & & \\
\hline $\begin{array}{l}\text { Grade of invasive } \\
\text { ductal carcinoma }(n=155)\end{array}$ & & & 10.604 & 0.001 & 0.268 & 0.001 & 2.365 & $1.263-4.430$ \\
\hline I & 62.5 & 37.5 & & & & & & \\
\hline II & 60.4 & 39.6 & & & & & & \\
\hline III & 26.3 & 73.7 & & & & & & \\
\hline
\end{tabular}

CI, confidence interval; HR, hazard ratio.

The data of the present study have demonstrated that several typical mammographic features are correlated with certain indices of immunohistochemistry and pathology, and lymph node metastasis status. The aforementioned evidence may reflect tumor attributes to a certain extent.

In terms of the HER2 expression level, the data indicated that the ratio of malignant calcifications on mammogram was significantly high in HER2-positive cases. In particular, differences existed between the HER2-positive or -negative group on mammogram. A study by Gajdos et al (14) suggested that calcifications were associated with HER2 overexpression. The presence of calcifications in a mass or segmental calcifications on mammography were significantly associated with a positive HER2 status. Studies have been conducted on ER-negative breast cancer patients, which demonstrated that in the ER-negative group, HER2-positive breast cancers are more likely to be irregular masses, with spiculated margins associated with pleomorphic calcifications, whereas the HER2-negative breast cancers have been more frequently identified as round/variform-shaped masses with indistinct margins and have shown a great diversity of morphological types of calcifications comparatively (15). Thus far, a few studies have reported the association between HER2 overexpression of various types of tumor and malignant-appearing calcifications with regard to ductal carcinoma in situ (DCIS), non-palpable breast carcinomas and invasive breast carcinomas $(3,13,16)$. These studies demonstrated that, regardless of the type, the malignant calcifications on mammography were correlated with HER2 status, tending to exist in the HER2 overexpression cases. As for the IDCs, the results were concordant with previous studies conducted concerning this aspect (3). Based on the aforementioned evidence, it may be inferred that patients who exhibit the malignant calcifications on mammography tend to be HER2 overexpressed when they are newly diagnosed. As is widely known, the HER2 status is an important prognostic factor for overall survival and disease-free survival of patients with breast cancer (17), which is closely associated with the HER2 receptor-targeted trastuzumab therapy.

Previous studies have demonstrated the association between p53 and Ki-67 expression with mammography. Gilliland et al (18) concluded that rapidly growing and aggressive tumors are responsible for a considerable amount of breast cancer detection failure by mammography. The identification of cancer within 12 months following a negative mammogram is defined as 'interval breast cancer.' The dysregulation of the cell cycle and potential genetic instability were measured by p53 expression, whereas the proliferation rate of the tumor was measured by the Ki-67 index. The results of the study indicated that the proportion of pleomorphic calcifications on mammography in p53-positive expression cases was significantly higher compared with the negative cases. The rates of evident breast mass on mammography in the high Ki-67-expression level group were significantly higher than those with low expression levels. The study by Porter et al (19) also indicated that screening mammography may miss certain rapidly proliferating, high-grade tumors. Thus, the studies highlight that more concerns should be taken for patients with pleomorphic calcifications or evident breast mass on mammogram. It is likely that these mammographic appearances are correlated with p53 or Ki-67 expression status, which are prognostic factors of great importance $(20,21)$.

In addition, the present study examined the correlation between the mammographic feature of nipple retraction and PR expression status. No specific mammographic findings were significantly associated with ER or PR status in the study by Gajdos et al (14). Another study found that non-spiculated margins or hyperdense masses were associated with a negative ER status (22). The results of the data in the present study showed that the presentation ratio of the nipple retraction symptom was significantly higher in PR-positive expression patients compared with negative expression of PR. Therefore, this finding may indicate that patients who showed symptoms of nipple retraction on mammogram prior to surgery were likely to exhibit PR-positive expression, which may provide particular guidance for further endocrine treatment (23).

As for the pathological characteristics of tumors, the results of the present study demonstrated significant differences between the tumor size, various histological types and grades of IDC with mammographic features, malignant or pleomorphic calcifications, and the shape of the breast mass on the mammogram. Among the type of evident mass on mammogram, irregular shapes of mass were more frequently 
present in tumors with grade 3 IDC. By contrast, the studies by Rotstein and Neerhut (24) and Lamb et al (25) indicated that high-grade IDCs may paradoxically exhibit features similar to those of benign breast masses, including a well-defined margin. Masses with non-spiculated margins on mammography were associated with a higher histological grade (22).

To a certain extent, it can account for the phenomenon that tumor attributes contribute to the variety of mammographic appearance types. However, due to the fact that the majority of patients in the present study were IDC type, the number of IDC accompanied by DCIS or other histological types was relatively small. Therefore, further studies are required to clarify this aspect. The aforementioned information on mammography can offer accurate pre-operative evaluation for breast-conserving surgery.

Regarding the nodal involvement, the data have demonstrated that pleomorphic calcifications, overlying skin thickening or dimpling on mammogram were more frequently present in the positive lymph node status group. Awareness of this information prior to surgery would aid clinicians in formulating the most suitable choices of surgical treatment modality for patients, including mastectomy or breast-conserving surgery (26). Another study revealed that the presence of calcifications alone or masses associated with calcifications on mammography was significantly associated with positive extensive intraductal component, and this contraindicates breast-conserving surgery and other mammographic features, including irregular shape, indistinct margin, calcifications within a mass and segmental calcifications (23).

In conclusion, it is of note that there are significant differences between the mammographic appearances with breast carcinoma attributes. The correlation of mammography image features and clinical and pathological characteristics exist in IDCs. Based on these findings, we believe that the mammography image appearances may reflect certain biological behaviors of tumors prior to surgery, which are useful for future evaluation and treatment of patients.

\section{Acknowledgements}

The present study was supported by the Program for the Applied Basic Research and Cutting-edge Technology Project of Tianjin Science and Technology Commission to Professor Cao (grant no. 11JCZDJC28000).

\section{References}

1. Tabar L, Yen MF, Vitak B, Chen HH, Smith RA and Duffy SW: Mammography service screening and mortality in breast cancer patients: 20-year follow-up before and after introduction of screening. Lancet 361: 1405-1410, 2003.

2. Tabar L, Tony Chen HH, Amy Yen MF, Tot T, Tung TH, Chen LS, Chiu YH, Duffy SW and Smith RA: Mammographic tumor features can predict long-term outcomes reliably in women with 1-14-mm invasive breast carcinoma. Cancer 101: 1745-1759, 2004.

3. Seo BK, Pisano ED, Kuzimak CM, Koomen M, Pavic D, Lee Y, Cole EB and Lee J: Correlation of HER-2/neu overexpression with mammography and age distribution in primary breast carcinomas. Acad Radiol 13: 1211-1218, 2006.

4. Yang WT, Hennessy B, Broglio K, Mills C, Sneige N, Davis WG, Valero V, Hunt KK and Gilcrease MZ: Imaging differences in metaplastic and invasive ductal carcinomas of the breast. AJR Am J Roentgenol 189: 1288-1293, 2007.
5. Zhao J, Liu H, Wang M, Gu L, et al: Characteristics and prognosis for molecular breast cancer subtypes in Chinese women. J Surg Oncol 100: 89-94, 2009.

6. Breast Imaging Research Centre, American College of Radiology and American College of Breast Imaging Reporting and Data System. American College of Breast Imaging Reporting and Data System. Am Coll Radiol, 1998.

7. Ildefonso C, Vazquez J, Guinea O, et al :The mammographic appearance of breast carcinomas of invasive ductal type: relationship with clinicopathological parameters, biological features and prognosis. Eur J Obstet Gynecol Repord Biol 136: 224-231, 2008.

8. Broberg A, Glas U, Gustafsson SA, Hellström L, Somell A: Relationship between mammographic pattern and estrogen receptor content in breast cancer. Breast Cancer Res Treat 3: 201-207, 1983.

9. Paradiso A, Ventrella V, Farchi G, et al: Mammographic aspect, cell kinetics and hormone receptor status of operable breast cancer. Oncology 50; 104-109, 1993.

10. Wilson TE, Helvie MA, Oberman HA, Joynt LK:Pure and mixed mucinous carcinoma of the breast: pathologic basis for differences in mammographic appearance. AJR Am J Roentgenol 165: 285-289, 1995.

11. Ciatto S and Zappa M: A prospective study of the value of mammographic patterns as indicators of breast cancer risk in a screening experience. Eur J Radiol 17: 122-125, 1993.

12. Matsuda M, Yoshimoto M, Iwase T, et al: Mammographic and clinicopathological features of mucinous carcinoma of the breast. Breast Cancer 7: 65-70, 2000

13. Günhan-Bilgen I and Oktay A: Tubular carcinoma of the breast: mammographic, sonographic, clinical and pathologic findings. Eur J Radiol 61: 158-162, 2007.

14. Gajdos C, Tartter PI, Bleiweiss IJ, et al: Mammographic appearance of nonpalpable breast cancer reflects pathologic characteristics. Ann Surg 235: 246-251, 2002.

15. Enache DE, Georgescu CV and Pătrană N: Negative estrogen-receptor invasive breast carcinoma: mammographic aspects, correlations with HER2/neu oncoprotein status. Rom J Morphol Embryol 53 (3 Suppl): 755-762, 2012.

16. Evans AJ, Pinder SE, Ellis IO, et al: Correlations between the mammographic features of ductal carcinoma in situ (DCIS) and C-erbB-2 oncogene expression. Nottingham Breast Team. Clin Radiol 49: 559-562, 1994.

17. Slamon DJ, Clark GM, Wong SG, Levin WJ, Ullrich A and McGuire WL: Human breast cancer: correlation of relapse and survival with amplification of the HER-2/neu oncogene. Science 235: 177-182, 1987.

18. Gilliland FD, Joste N, Stauber PM, Hunt WC, Rosenberg R, Redlich G and Key CR: Biologic characteristics of interval and screen-detected breast cancers. J Natl Cancer Inst 92: 743-749, 2000.

19. Porter PL, El-Bastawissi AY, Mandelson MT, Lin MG, Khalid N, Watney EA, Cousens L, White D, Taplin S and White E: Breast tumor characteristics as predictors of mammographic detection: comparison of interval- and screen-detected cancers. J Natl Cancer Inst 91: 2020-2028, 1999.

20. Sirvent JJ, Fortuño-Mar A, Olona M and Orti A: Prognostic value of $\mathrm{p} 53$ protein expression and clinicopathological factors in infiltrating ductal carcinoma of the breast. A study of 192 patients. Histol Histopathol 16: 99-106, 2001.

21. Jalava P, Kuopio T, Juntti-Patinen L, Kotkansalo T, Kronqvist P and Collan Y: Ki67 immunohistochemistry: a valuable marker in prognostication but with a risk of misclassification: proliferation subgroups formed based on Ki67 immunoreactivity and standardized mitotic index. Histopathology 48: 674-682, 2006.

22. Shin HJ, Kim HH, Huh MO, Kim MJ, Yi A, Kim H, Son BH and Ahn SH: Correlation between mammographic and sonographic findings and prognostic factors in patients with node-negative invasive breast cancer. Br J Radiol 84: 19-30, 2011.

23. Liu S, Chia SK, Mehl E, Leung S, Rajput A, Cheang MC and Nielsen TO: Progesterone receptor is a significant factor associated with clinical outcomes and effect of adjuvant tamoxifen therapy in breast cancer patients. Breast Cancer Res Treat 119: 53-61, 2010.

24. Rotstein AH and Neerhut PK: Ultrasound characteristics of histologically proven grade 3 invasive ductal breast carcinoma. Australas Radiol 49: 476-479, 2005.

25. Lamb PM, Perry NM, Vinnicombe SJ and Wells CA: Correlation between ultrasound characteristics, mammographic findings and histological grade in patients with invasive ductal carcinoma of the breast. Clin Radiol 55: 40-44, 2000.

26. Kollias J, Gill PG, Beamond B, et al: Clinical and radiological predictors of complete excision in breast-conserving surgery for primary breast cancer. Aust N Z J Surg 68: 702-706, 1998. 